DOI: $10.21767 / 2171-6625.100002$

\title{
CT Findings of Early Post Operative Neurological Complication of Cardiovascular Surgeries
}

\begin{abstract}
Introduction: The incidence of neurological complications related to cardiovascular surgeries is comparatively very high and associated with high morbidity and mortality. The aim of this study is to establish not only the use of non-contrast computed tomography in detecting the cause of neurological problems but also to evaluate the various spectrums of findings associated with various types of cardiovascular surgeries.
\end{abstract}

Method: We retrospectively analyzed all the non-contrast computed tomography head of the postoperative cardio-vascular surgeries patients done in immediate postoperative period ( $<7$ days).

Result: 45 (6.7\%) patients developed neurological complications in the early post-operative period which comprised of our study group. Out of 45 patients, $08(18 \%)$ patients were of pediatric age group ranging who underwent surgeries for congenital complex cardiac disorders. Out of 45 patients presenting with neurological symptoms, 15 (33\%) patients had focal deficit (stroke) and $30(77 \%)$ patients had non-focal deficit (like seizure, delirium or cognitive impairment). Stroke patients had more possibility to have positive CT scan findings than NFD. Out of 45 patients, $40(88 \%)$ had positive CT scan findings and five patient had normal NCCT head. The various types of positive CT scan findings were- 19 ischemic infarct, 04 intra-parenchymal hemorrhages, 17 subdural hemorrhage, 03 sub-arachnoid hemorrhage and 01 cerebro-vascular thrombosis.

Conclusion: Non-contrast computed tomography of head is very useful in early postoperative neurological complication in cardio-vascular surgeries not only in diagnosing the complication but also managing accordingly.

Keywords: Neurological complications; Cardiovascular surgery; CT scan

\section{Dashottar S', Singh AK', Suhag V ${ }^{3}$, Sunita BS ${ }^{4}$, Johri S ${ }^{5}$, Satija L ${ }^{1}$, Garg A ${ }^{5}$, Bindra $\mathrm{HS}^{5}$, Singh $\mathbf{R K}^{6}$ and Pannu SK}

1 Department of Radio-diagnosis, Military Hospital (C TC), Pune, India

2 Department of Radio-diagnosis, Army Hospital R\&R, Delhi, India

3 Department of Radiotherapy, Army Hospital R\&R, Delhi, India

4 Department of Pathology, Base Hospital, Delhi, India

5 Cardiothoracic Vascular Surgery Department, Military Hospital (CTC), Pune, India

6 Command Hospital (Eastern Command), Kolkata, India

7 Department of Radio-diagnosis, Army Hospital R\&R, Delhi, India

\section{Corresponding author: Virender Suhag}

” virendersuhag@gmail.com

Radiotherapy Army Hospital (R\&R) Delhi Cantt, India, +918826804584

Tel: +918826804584

Citation: Dashottar S, Singh AK, Suhag V, et al. CT Findings of Early Post Operative Neurological Complication of Cardiovascular Surgeries. J Neurol Neurosci. 2016, 6:1.

Received: February 09, 2015; Accepted: April 06, 2015; Published: April 09, 2015

\section{Introduction}

Neurological complications (NC) are a major cause of morbidity and mortality during the immediate and early postoperative period following cardiovascular surgeries (CS). They add to the consumption of health care resources and lead to functional limitations in surviving patients. The understanding of their etiology, pathogenesis, prevention, and management on the part of the clinicians who treat these patients is under constant development. Despite the best efforts made by treating clinicians, the incidence of $\mathrm{NC}$ in these patients is not reducing due to several risk factors like their age, various associated comorbidities and overall vascular deteriorations [1]. The pathogenesis of the cerebral infarction related to cardiovascular surgeries is due to several micro emboli originating in the cardiopulmonary bypass circuit or cardiac chambers or atheromatous plaque from arch of aorta. These microemboli leads to cerebral hypoperfusion finally causing ischemic lesions mainly in the watershed areas $[2,3]$. Various other mechanisms anticipated to elucidate the cerebral dysfunction consist of development of post operative 
cerebral edema, inflammatory cascade activation and gaseous or lipid particles micro-emboli [4]. Moody et al. [5] proposed that following bypass surgery, the cerebral arterioles and capillaries dilate due to microemboli. The development of post operative encephalopathy and delirium is usually due to adverse effects of anesthetic drugs, metabolic changes, ischemic lesions, hypotension, etc.

There are few studies available in the literature who have established the use of the non-contrast computed tomography (NCCT) of the head in evaluating correction in the immediate and early post-operative period ( $<7$ postoperative days) following cardiovascular surgeries. The aim of this study is to establish not only the use of NCCT in detecting the cause of NC but also to evaluate the various spectrums of $\mathrm{CT}$ findings associated with various types of cardiovascular surgeries.

\section{Material and methods}

We retrospectively analyzed all the NCCT heads of the postoperative cardiovascular surgeries patients done in immediate and early post-operative period ( $<7$ days) in the department of Radio-diagnosis between Mar 2013 to Sep 2014. The CT scan was done on 256 slice MDCT (Philips). The medical records of all these CS patients were then analyzed for various variants like total number of patients underwent cardiovascular surgeries, various types of CS done during the study period, demographic information, associated co-morbidities, various types of NC, post-operative data, diagnosis and various spectrum of CT findings in the brain.

\section{Inclusion criteria}

Patients of all age group in which NCCT head was done for evaluation of NC in early post operative period (POP) after CS from Mar 2013 to Aug 2014.

\section{Exclusion criteria}

1. All the post operative CS patients in whom NCCT was done after 7days POP.

\section{Post operative CS patients in which repeat NCCT was done.}

Patients were broadly classified into two groups based on their NC like Neurological/Focal deficit (ND/FD like stroke) and nonfocal deficit (NFD like seizures, delirium, cognitive impairment in absence of ND). The outcome data of these subgroups were then analyzed along with the findings on NCCT head. The outcome of these CS patients was broadly classified as: a) Type of NC, b) type of radiographic findings associated with the type of neurological injury, and c) various spectrum of CT findings.

\section{Results}

The total number of CS done in our hospital during the study period from Mar 2013 to Sep 2014 was 669, the distribution of which is given in Table 1. Out of 669 CS, 45 (6.7\%) patients developed NC in the early POP which constituted our study group. These patients were clinically evaluated for their symptoms
Table 1 Various types of cardiac surgeries done during the study period.

\begin{tabular}{|c|c|c|}
\hline $\begin{array}{c}\text { Type of Operation } \\
\text { Coronary artery bypass graft } \\
\text { (CABG) }\end{array}$ & 238 & $35.6 \%$ \\
\hline $\begin{array}{c}\text { CABG + Valve replacement } \\
\text { surgeries (VRS) }\end{array}$ & 17 & $2.5 \%$ \\
\hline $\begin{array}{c}\text { Valve replacement surgeries } \\
\text { Congenital complex cardiac } \\
\text { disorders (CCCD) }\end{array}$ & 148 & $22.1 \%$ \\
\hline $\begin{array}{c}\text { Other open \& closed heart } \\
\text { operations }\end{array}$ & 17 & $36.2 \%$ \\
\hline $\begin{array}{c}\text { Aortic dissections \& } \\
\text { aneurysms }\end{array}$ & 7 & $2.5 \%$ \\
\hline Total & 669 & $1 \%$ \\
\hline
\end{tabular}

Table 2 No. of patients with neurological complications in various types of CS.

\begin{tabular}{|c|c|c|c|}
\hline S.No & \multicolumn{1}{|c|}{ Type of cardiac surgery } & $\begin{array}{c}\text { No. of patients } \\
(45)\end{array}$ & Percentage \\
\hline 1. & CABG & 19 & $42.2 \%$ \\
\hline 2. & Valve replacement surgeries (VRS) & 14 & $31 \%$ \\
\hline 3. & Aortic surgery & 1 & $2.2 \%$ \\
\hline 4. & ASD closure surgeries & 2 & $4.4 \%$ \\
\hline 6. & Infective endocarditis & 1 & $2.2 \%$ \\
\hline 7. & Pediatric cardiac surgeries & T8 & $18 \%$ \\
\hline
\end{tabular}

and classified into two major groups; first group of 15 patients with focal deficit and second group of 30 patients without focal deficit. These patients were then further evaluated by NCCT head to know the cause of neurological problems. Out of 45 patient who developed NC, 8 (18\%) patients were of pediatric age group ranging from 2 months to 16 yrs (mean age was 8 yrs) who underwent surgeries for congenital complex cardiac disorders (CCCD). All these patients were male and were not associated with any of the co-morbidities. Remaining 37 patients (82\%) were adults ranging from 28 yrs to 70 yrs (average age is 49 years) with male: female ratio being $2: 1$. In the adult patients found to have previous co-morbid conditions; hypertension, IHD, diabetes mellitus and cerebrovascular accidents accounted for $37 \%, 30 \%$, $18 \%$ and $15 \%$ of cases respectively. Out of 37 patients, 7 (19\%) patients were active smoker at the time of CS.

Out of 45 patients who developed correction following cardiovascular surgeries, the type and number of underlying cardiovascular surgical procedures are given in Table 2 . The most common surgery involved was CABG followed closely with valve replacement surgeries (VRS), accounting for 19 (42.2\%) and 14 (31\%) cases respectively. Out of the 669 patients undergoing various forms of cardiovascular surgeries, the incidence of patients developing correction in various categories of surgeries is shown in Table 3. ASD closure surgeries and infective endocarditis subset of patients (17.6\%) formed the highest group followed by valve replacement surgeries (9.5\%) and CABG (7.9\%) to develop immediate/early post-op correction. Out of the various cardiac 
Table $\mathbf{3}$ Incidence of neurological complications in various types of cardiac surgeries.

\begin{tabular}{|c|c|c|c|}
\hline S.No & $\begin{array}{c}\text { Type of cardiac } \\
\text { surgery }\end{array}$ & $\begin{array}{c}\text { No. of patients developed } \\
\text { neurological complications/ } \\
\text { total no. of type of CS done }\end{array}$ & Percentage \\
\hline 1. & CABG & $19 / 238$ & $7.9 \%$ \\
\hline 2. & $\begin{array}{c}\text { Valve replacement } \\
\text { surgeries }\end{array}$ & $14 / 148$ & $9.5 \%$ \\
\hline 3. & CABG + VRS & $1 / 17$ & $5.8 \%$ \\
\hline 4. & Aortic surgery & $1 / 7$ & $7.6 \%$ \\
\hline $5 . \quad$ & $\begin{array}{c}\text { ASD closure } \\
\text { surgeries \& Infective } \\
\text { endocarditis }\end{array}$ & $3 / 17$ & $3.3 \%$ \\
\hline 6. & $\begin{array}{c}\text { Pediatric cardiac } \\
\text { surgeries }\end{array}$ & $8 / 242$ & \\
\hline
\end{tabular}

Table 4 Type of positive findings on CT scan in FD vs NFD patients.

\begin{tabular}{|c|c|c|c|}
\hline S.No & NCCT findings & FD & NF \\
\hline & Total no. of patients & 15 & 30 \\
\hline 1. & Infarcts & $11(73 \%)$ & $08(27 \%)$ \\
\hline 2. & SDH & $2(13 \%)$ & $14(47 \%)$ \\
\hline . & $\mathrm{ICH}$ & $1(7 \%)$ & $2(6.5 \%)$ \\
\hline 4. & SAH & $0(0 \%)$ & $2(6.5 \%)$ \\
\hline 5. & NAD & $1(7 \%)$ & $4(13 \%)$ \\
\hline
\end{tabular}

Table 5 Types of Positive CT scan findings in Adult and Pediatric patients.

\begin{tabular}{|c|c|c|c|}
\hline S.No & $\begin{array}{r}\text { Type of positive CT } \\
\text { scan findings }\end{array}$ & $\begin{array}{r}\text { Frequency of } \\
\text { positive CT scan (46) }\end{array}$ & Percentage \\
\hline 1. & $\begin{array}{r}\text { Ischemic infarct } \\
\text { Intra-parenchymal } \\
\text { hemorrhage }\end{array}$ & 20 & $43.5 \%$ \\
\hline 3. & SDH & 17 & $8.7 \%$ \\
\hline 4. & SAH & 3 & $37 \%$ \\
\hline 5. & CVT & 1 & $6.5 \%$ \\
\hline 6. & $\begin{array}{r}\text { Diffuse cerebral } \\
\text { edema }\end{array}$ & 1 & $2.1 \%$ \\
\hline
\end{tabular}

Table 6 Positive CT scan findings in Pediatric patients.

\begin{tabular}{|c|l|c|c|}
\hline S.No & $\begin{array}{c}\text { Type of positive CT } \\
\text { scan findings }\end{array}$ & $\begin{array}{c}\text { Frequency of } \\
\text { positive CT scan (8) }\end{array}$ & Percentage \\
\hline 1. & Ischemic infarct & 4 & $50 \%$ \\
\hline 2. & SDH & 2 & $25 \%$ \\
\hline 3. & $\begin{array}{l}\text { Intra-parenchymal } \\
\text { hemorrhage }\end{array}$ & $12.5 \%$ \\
\hline 4. & $\begin{array}{l}\text { Diffuse cerebral } \\
\text { edema }\end{array}$ & 1 & $12.5 \%$ \\
\hline
\end{tabular}

valve surgeries (CVS) done in our hospital, 9 were MVR, 3 were AVR and 2 were DVR.Type of positive findings on CT scan in FD and NFD patients is given as Table 4 . Out of 45 patients presenting with NC, 15 (33\%) patients had FD (stroke) and 30 (77\%) patients had NFD (like seizure, delirium or cognitive impairment). In FD group, $14 / 15$ i.e. $93 \%$ patients had positive CT scans as compared to NFD group (26/30 i.e. $83 \%$ ); thus stroke (FD) patients were more likely to have positive CT scan findings than NFD. In the FD group, 11 patients (73\%) developed acute/subacute infarct; while 8 patients $(27 \%)$ developed infarct in NFD group. Hemorrhage (SDH, ICH and SAH) was more seen in NFD group where 18 patients (60\%) developed hemorrhage; as compared to FD group where 3 patients (20\%) developed hemorrhage.

Out of total 45 patients who developed correction, 40 (88\%) had positive CT scan findings and five patients had normal NCCT head. However, when all the findings were analyzed, it was found that the total number of positive CT scans was more than the number of the patients with positive CT scan findings, as few patients had more than one finding.A total number of 46 positive CT scan findings were noted, 8 in pediatric patients and 38 in adult age group; as given in Table 5. Taken together, ischemic infarct was the commonest CT finding as seen in $43.5 \%$ cases; followed by SDH (37\%). The CT findings in pediatric patients are given in Table 6. 8 pediatric patients developed NC in post CS period. In four patients (50\%), the CT scan findings were suggestive of ischemic infarct. Out of these 4 patients, two patients (25\%) had more than one arterial territory involved, more likely to be embolic phenomena. Second most common finding was SDH of variable extent, along the falx and tentorium, as seen in 2 out of these 8 cases (25\%). Intra-parenchymal hemorrhage and diffuse cerebral edema constituted 1 positive finding each. Single positive finding was seen in six (75\%) patients while one (12.5\%) patient had combination of two positive finding i.e. infarct and SDH both. 1 pediatric patient had normal CT scan.

Most frequent $\mathrm{CT}$ scan finding in adult was ischemic infarct as seen in 16 cases; and second most common CT scan finding was SDH which was noticed in 15 patients, as explained in Table 7. Remaining other findings was less frequently seen. Rare finding was CVT as evident in 1 case. The combination of positive CT scan findings was found in various types of CS. In CABG patients, two patients had ICH and SDH both, one patient had Infarct and SDH and one patient had SDH and SAH. In CVS, four patients had infarct and SDH both while one patient had $\mathrm{ICH}$ and SDH both. One patient of infective endocarditis found to have combination of SAH and Infarcts. Combination of three positive findings on CT scan was seen only in one case of Aortic surgery i.e. infarcts, SAH and CVT. The commonest single positive CT scan in CABG and CVS was ischemic infarct.

In acute/sub-acute ischemic infarcts the various arterial territories involved in different patients has been given as Table 8. $3(16 \%)$ patients had ICA territory infarct, 9 (47\%) patients had MCA territory infarct, $1(5 \%)$ patient had unilateral ACA territory infarct, and $3(16 \%)$ patients had posterior circulation infarct. Watershed infarcts were seen in $3(16 \%)$ patients. One patient had acute infarct of the posterior circulation, which was causing significant mass effect in the form of severe compression over the IV ventricle leading to obstructive hydrocephalus. One patient had extensive bilateral ICA infarcts involving almost the entire bilateral cerebral hemispheres also had associated cerebrovascular thrombosis of the deep venous system. 
Table 7 Type of Positive CT Scan findings (In adult patients).

\begin{tabular}{|c|c|c|c|}
\hline S.No & $\begin{array}{c}\text { Type of positive CT } \\
\text { scan findings }\end{array}$ & $\begin{array}{c}\text { Frequency of } \\
\text { positive } \\
\text { CT scan (38) }\end{array}$ & Percentage \\
\hline 1. & $\begin{array}{c}\text { Ischemic infarct } \\
\text { Intra-parenchymal } \\
\text { hemorrhage }\end{array}$ & 16 & $42.1 \%$ \\
\hline 2. & SDH & 15 & $7.9 \%$ \\
\hline 3. & SAH & 3 & $39.5 \%$ \\
\hline 4. & CVT & T1 & $7.9 \%$ \\
\hline 5. & & & $2.6 \%$ \\
\hline
\end{tabular}

Table 8 Various arterial territories involved by the Infarcts in different patients.

\begin{tabular}{|c|c|c|c|c|}
\hline S.No & $\begin{array}{c}\text { Arterial territory of } \\
\text { Infarct }\end{array}$ & Bilateral & Unilateral & Percentage \\
\hline 1 & ICA & 2 & 1 & $16 \%$ \\
\hline 2 & MCA & 4 & 5 & $47 \%$ \\
\hline 3 & ACA & 0 & 1 & $05 \%$ \\
\hline 4 & Posterior circulation & 2 & 1 & $16 \%$ \\
\hline 5 & Watershed infarcts & 0 & 3 & T16\% \\
\hline
\end{tabular}

Table 9 Location of SDH ( $n=17)$.

\begin{tabular}{|c|c|c|c|}
\hline S.No & TLocation of SDH & No. of cases & Percentage \\
\hline 1. & $\begin{array}{l}\text { Along Cerebral } \\
\text { convexity }\end{array}$ & 3 & $17.6 \%$ \\
\hline 2. & $\begin{array}{l}\text { Along Cerebellar } \\
\text { hemispheres }\end{array}$ & 2 & $11 . \%$ \\
\hline 3. & $\begin{array}{l}\text { Along falx \& superior } \\
\text { surface of tentorium }\end{array}$ & 10 & $59 \%$ \\
\hline 4. & $\begin{array}{l}\text { Supra \& infra- } \\
\text { tentorium both }\end{array}$ & 2 & $11.7 \%$ \\
\hline
\end{tabular}

SDH was seen in 17 patients as is evident from Table 9, of whom 10 patients (59\%) had along the posterior falx and superior surface of the tentorium, $3(17.6 \%)$ patients had along the cerebral convexities, $2(11.7 \%)$ patients had in the posterior fossa along the bilateral occipital bones and in $2(11.7 \%)$ patients in both supra-tentorium and infra-tentorium. Diffuse cerebral edema (DCE) and/or significant mass effect were usually seen in either extensive infarcts or on combination of two or more positive findings like infarcts, ICH, SAH and SDH. Out of 40 patients, 7 patients $(17.5 \%)$ had diffuse cerebral edema and 10 patients (25\%) had significant mass effect.

(Figures 1-5)

\section{Discussion}

We carried out a retrospective study of all the NCCT heads done in our department from Mar 2013 to Aug 2014 on the post cardiac surgery patients who developed various NC in the immediate POP. The total number of CS done in our hospital during the study period was 669 . The most common surgery performed was that for congenital complex cardiac disorders (CCCD), which was performed in $36.2 \%$ patients; followed closely by coronary artery

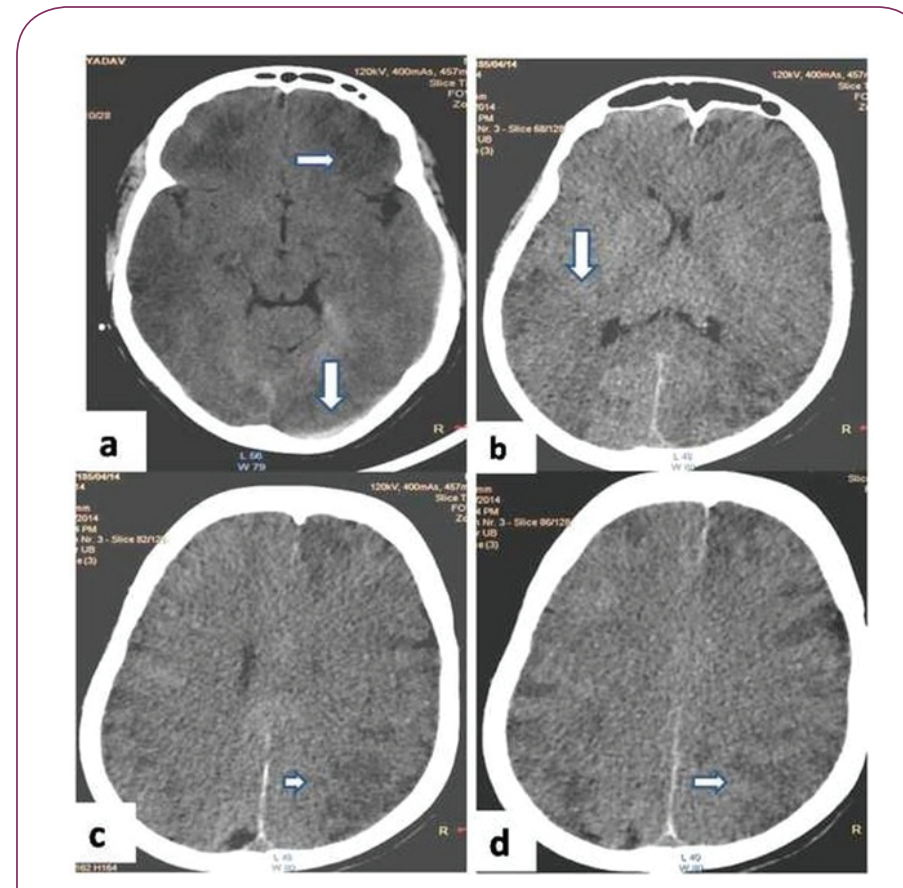

Figure 1 NCCT scans shows different types of ischemic infarct in different patients with focal deficit type of neurological complication in post cardiac surgery patients. (a) NCCT axial image of $38 \mathrm{yrs}$ old male patient case of MVR who had left sided hemiplegia showed ischemic infarcts in the right temporal and watershed infarcts in bilateral frontal lobes with mild SDH along the left occipital and on the superior surface of tentorium. (b), (c) and (d) scan of 55 yrs old patient operated c/o infective endocarditis on ventilator had NFD shows (b) ischemic infarcts in the bilateral MCA territory, (c) and (d) scan of the same patients shows multifocal small hypodense areas of varying sizes in the cortical and sub-cortical white matter of bilateral MCA and left ACA territories with diffuse cerebral edema likely to be embolic.

bypass graft (CABG) which was performed in $35.6 \%$ cases.

The most important cause of morbidity and mortality in the immediate POP following cardiac surgeries are NC. The incidence of neurological deficits following CS varies from $25 \%$ to $79 \%$ while $6 \%$ comprises of FD [6-17]. In the study by Beaty et al. the incidence of NC in early POP of post CS patient was 6.1\% [18]. In our study the incidence of NC in the early POP of CS patients was $6.7 \%$ and thus our findings corroborate those of Beaty and colleagues. In our study, amongst the patients developing correction following cardiac surgeries, the most common surgery involved was CABG followed closely with valve replacement surgeries (VRS), accounting for 19 (42.2\%) and 14 (31\%) cases respectively.

The average age of the adult patients was 49 years, with male: female ratio of 2:1. These patients were usually associated with co-morbidities, highest incidence of association with the co-morbidity was of hypertension (37\%) and second common was IHD (30\%). According to the Kurodo et al. the incidence of NC in CABG (11\%) was higher as compared to CVS (7\%) due to the coexisting cerebro-vascular disease and prolonged cardiopulmonary bypass time which in turn leads to cerebral embolism 


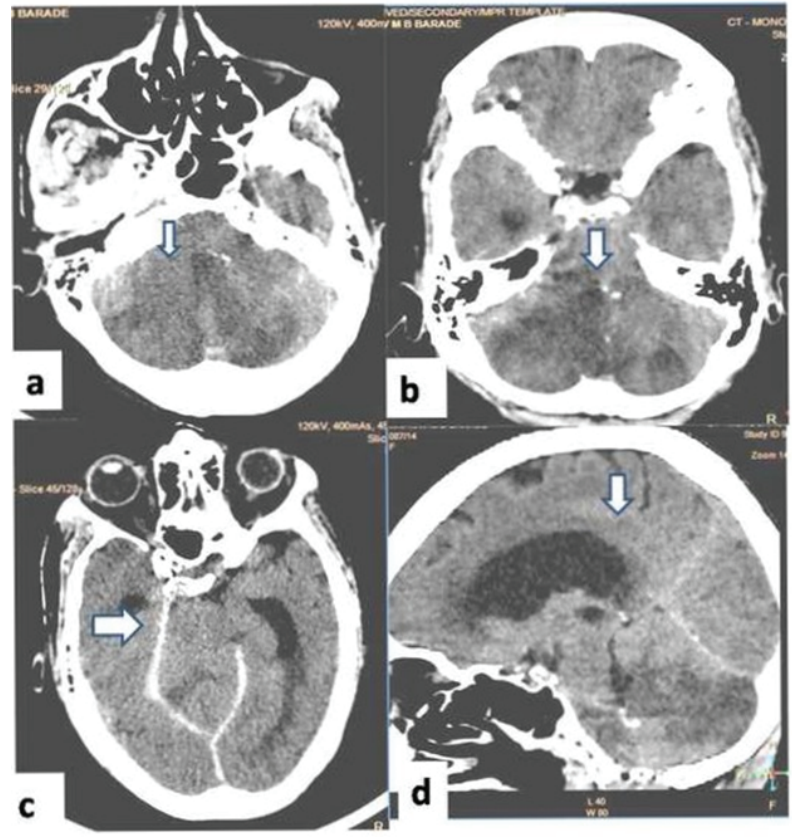

Figure 2 NCCT scan of a 60 yrs old patient case of CABG developed NFD type of neurological complication. (a) and (b) axial images shows extensive bilateral cerebellar infarcts compressing the IV ventricle causing obstructive hydrocephalus. (c) axial image shows mild SDH along the superior surface of tentorium. (d) sagittal image shows dilated lateral and III ventricles with mild periventricular ooze.
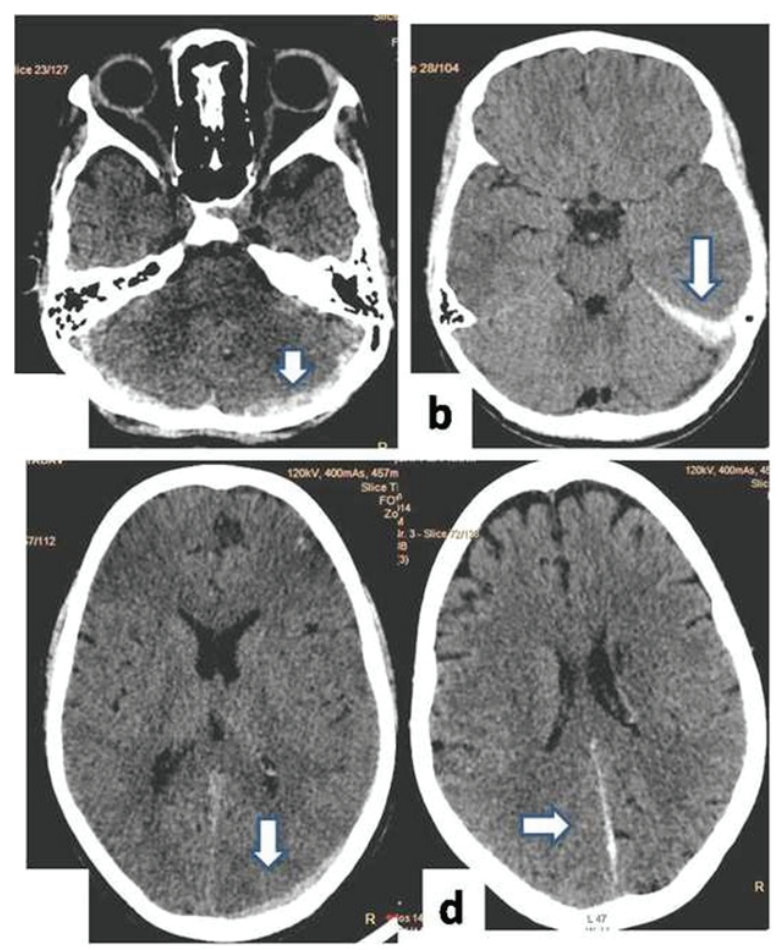

Figure 3 NCCT scans axial images of different patient shows different location of SDH, (a) shows SDH along bilateral cerebellar hemispheres, (b) SDH along tentorium on left side, (c) SDH along left occipital lobe, (d) SDH along posterior falx.

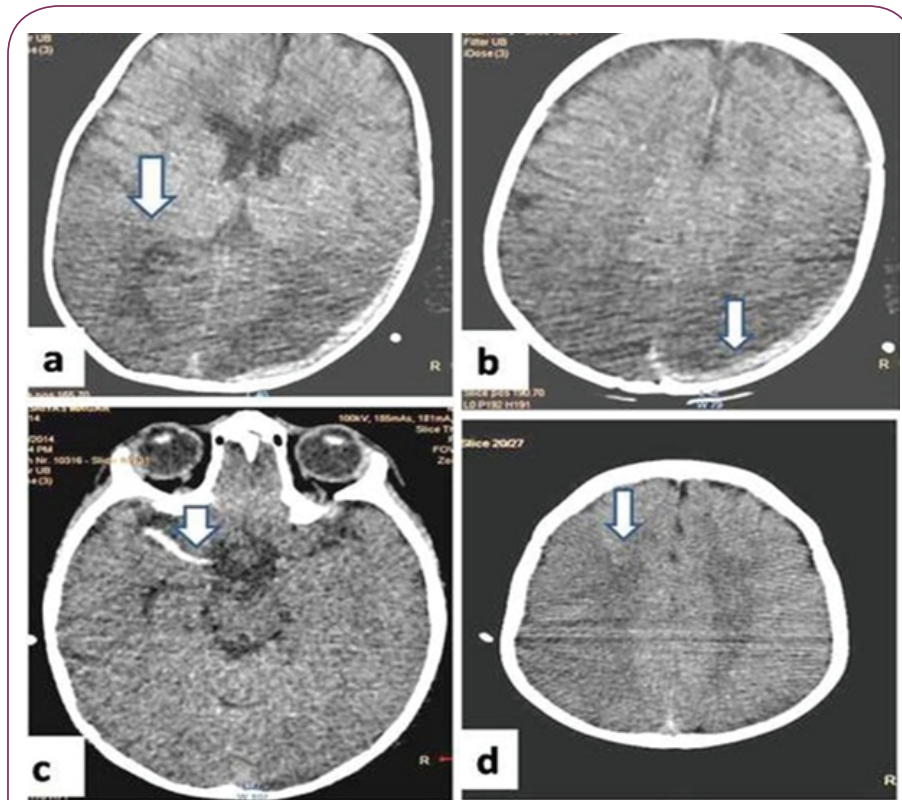

Figure 4 NCCT scans axial images (a) and (b) scans of $01 \mathrm{yr}$ old male baby operated case of TOF had ischemic infarcts in bilateral occipitoparietal region with mild SDH along left occipital region. (c) and (d) axial images of $01 \mathrm{yr}$ old operated case of situs inversus with pulmonary stenosis showed hyperdense thrombus in Right MCA with acute ischemic infarct in ipsilateral MCA territory.
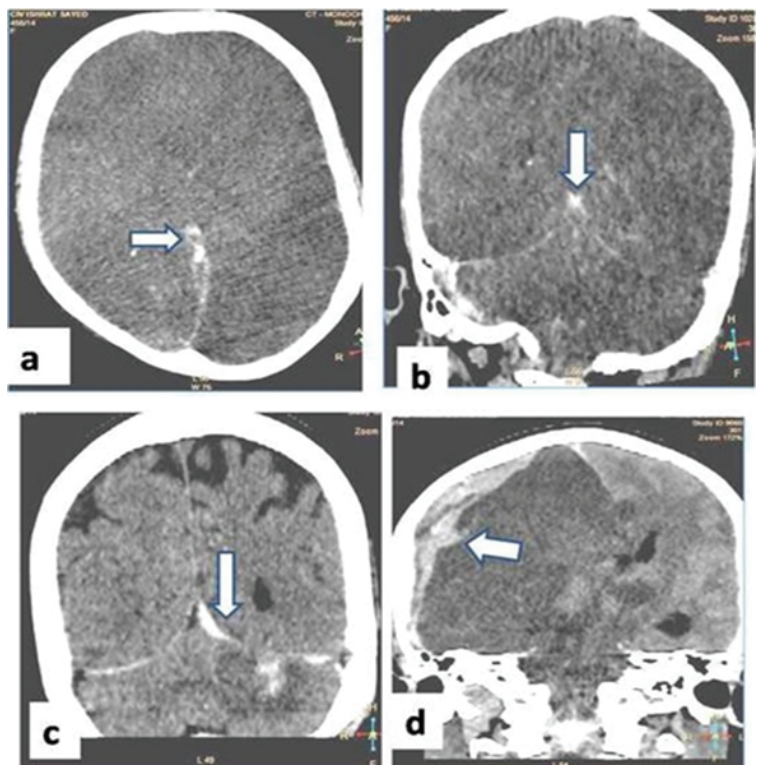

Figure 5 NCCT scans (a) and (b) axial and coronal images of $45 \mathrm{yrs}$ old female patient operated case of descending thoracic aortic aneurysm had extensive multifocal ischemic infarcts bilateral cerebral and cerebellar hemispheres with diffuse brain edema and significant mass effect. Thrombus was seen in deep venous system. (c) NCCT coronal images $61 \mathrm{yrs}$ old case female patient post MVR and TVA shows hemorrhagic infarct superior portion of left cerebellar hemisphere and mild SDH along the tentorium. (d) $31 \mathrm{yrs}$ old female patient case of post DVR unconsciousness had extensive acute infarct Right ICA territory with SDH right cerebral hemisphere causing significant mass effect. 
and/ or cerebral hypo-perfusion. The other risk factors which are responsible for higher incidence are age, diabetes mellitus, hypertension, cerebrovascular disease, and cardiopulmonary bypass time [19]. It has been established by several studies that the incidence of ischemic stroke and motor deficit ranging from 2 to $6 \%$ in cases of myocardial revascularization is more than with valve replacement surgeries [6-10]. These are primarily related to systemic hypo-perfusion or peri-operative embolism dislocating from the cardiac chambers/aorta or combination of these two processes. In our study, when the incidence of correction in various subsets of surgeries was considered, it was observed that ASD closure surgeries and infective endocarditis patients (17.6\%) formed the highest group followed by valve replacement surgeries $(9.5 \%)$ and CABG $(7.9 \%)$ to develop post-op correction. These CS were usually done as emergency surgery and usually associated with dislodgment of the infected emboli in the cerebral circulation. In our study, the incidence of NC in VRS (9.5\%) were more as compared to the CABG $(7.9 \%)$ as the chances of emboli formation were more with valve surgeries than with CABG. So our study is not in agreement with the previous studies. The lowest incidence of NC was observed with aortic surgeries.

In the study of Beaty et al. the incidence of NFD was 55\% while FD as $45 \%$. They also found that the chances of positive CT scan finding was more with FD than with NFD (34\% in FD while $2 \%$ in NFD) [18]. In our study, the incidence of NFD type of NC in the CS patient was $77 \%$ while $33 \%$ had FD (stroke) type, i.e. the incidence of NFD type NC in the CS patient were more as compared to the FD. Thus our study is in agreement to previous study. The chances of positive CT scan finding was found to be significantly higher in FD than NFD (93\% in FD while $83 \%$ in NFD) as compared to previous study. It was observed in our study that in most of the cases of NC whether it was NFD or FD, had positive CT scan findings. Only in $13 \%$ of NFD and $7 \%$ of FD had normal CT scan. In this context our study is not in consensus with the previous study.

Beaty et al. found the incidence of ischemic infarct in FD vs. NFD as $20.1 \%$ vs. $0.48 \%$ while there was no difference in the incidence of hemorrhage in the two groups [18]. In our study the incidence of ischemic infarct in FD vs. NFD was $73 \%$ vs. $27 \%$ while the incidence of hemorrhage in the two groups was $20 \%$ vs. $60 \%$. So in our study we found the commonest CT scan finding in FD was ischemic infarct (73\%) while in NFD it was hemorrhage (60\%). Our study is not in agreement with the previous study. In the study of Beaty et al. the incidence of positive CT scan findings in FD was $83 \%$ acute/subacute infarct while $7 \%$ had hemorrhage while only in $2.4 \%$ of NFD the positive CT finding was seen [14]. In our study, $73 \%$ had acute/subacute infarct and $20 \%$ had hemorrhage as positive CT scan finding in FD while in NFD $60 \%$ of cases had hemorrhage and $27 \%$ had infarct. In this perspective the incidence of infarct in FD is almost similar to the previous study. However, in our study the incidence of infarct and hemorrhage in NFD and hemorrhage in FD were higher as compared to the previous study.

CT scan is the most widely and easily available neuro-imaging modality used for diagnosis and evaluation of these NC [20]. NCCT is the most common modality to find out the cause of immediate and early post-operative period NC occurring in the patients of CS $[6,7,13,17]$. It is used to evaluate the size, location and distribution of the infarct/hemorrhage. As compared to magnetic resonance imaging (MRI), NCCT is rapid, cheap, most widely used modality. NCCT is primarily used to differentiate hemorrhage from non-hemorrhagic stroke. Clinically, it is very important in CS patients as the management of these strokes are essentially different and to decide the use of anticoagulants for atrial fibrillation, presence of mechanical valves and deep vein thrombosis. Not only this, NCCT also delineates the exact size of ischemic stroke as the incidence of hemorrhagic transformation increases with increase in the size of infarct, which may alter the treatment in CS patients.

Lev and colleagues reported the sensitivity of NCCT in the stroke as 57 to $71 \%$ while in hyper -acute stroke ( $<6$ hrs) was 45 to $70 \%$ [21]. Despite the low sensitivity of NCCT, it is the most important initial modality to diagnose and differentiate the various causes of post-operative NC in CS patients [18]. The Contrast enhanced CT scan helps in localizing the vascular stenosis/occlusion in hyper-acute and acute infarcts and hence helps in determining the benefits of thrombolytic therapy in hyper-acute and acute infarcts [22,23]. However, in our study we have not done the contrast enhanced CT scan for diagnosing the various correction as only in five (11\%) patients the NCCT was found to be normal.

The most probable cause of NFD in post CS patient has been found to be micro-emboli which leads to diffuse cerebral dysfunction which causes subtle anatomic change which are difficult to be diagnose on neuro-imaging $[8,12,13,17,24]$. Pugsley $W$ et al. recommended the use of 40 microns filter in arterial line which reduces the release of micro-emboli in the circulation [24]. The incidence of intra-cranial hemorrhage in such patients is extremely rare $(<1 \%)$. In NFD type of NC is primarily due to metabolic cause, so in most of these cases NCCT usually shows no significant findings except in few cases watershed infarcts are seen primarily due to hypo-perfusion. Therefore, in such patients NCCT in immediate POP shows marginal benefits over significant health care cost [18].

In our study the incidence of positive CT scan finding in the patients who had NC in early post-operative period of CS was $88 \%$ and only $12 \%$ had normal CT scan. The commonest finding on NCCT head was ischemic infarct and second common was mild SDH along the falx and tentorium. In pediatric patients the incidence of ischemic infarct was $50 \%$ and SDH was $25 \%$ while in adults it was $42 \%$ and $39.5 \%$ respectively. Only one patient had three positive CT scan findings i.e. infarct, SDH and CVT. In the literature no such study has been found till date. Therefore, comparative analysis could not be done with any such similar previous study.

The highest incidence of single positive finding of infarct was found with CABG while highest incidence of SDH was seen with CVS. The most common combination of positive CT finding was infarct and SDH and was found more frequently in CVS. The second common combination of positive $\mathrm{CT}$ finding was $\mathrm{ICH}$ and SDH which was more frequently seen in CABG patients. The 
commonest territory of the ischemic infarct was seen involving the MCA and the incidence was found to be $47 \%$. 58\% of infarcts showed unilateral arterial territory involvement while $42 \%$ had bilateral involvement. The second common variety of unilateral infarct was of watershed type, in bilateral type the ICA and posterior circulations were equally involved. The commonest location of the SDH was found along the posterior falx and superior surface of the tentorium, as was evident in $59 \%$ of these cases. Second common location of SDH was seen along the cerebral convexities, seen in $17.6 \%$ cases.

In our hospital we also have a well-established pediatric cardiology and pediatric cardiac surgery departments which are doing sufficient number of pediatric cardiac surgeries. So we ha ve also included all the cases of pediatric CS who developed post-operative NC during our study period. In our study the pediatric CS patients who developed NC comprises of $18 \%$ of the total study population. All these patients were male and were not associated with any co- morbidity. Avila-Alvarez A et al. reported the incidence of acute NC in post CS pediatric patients as $4.2 \%$ [25]. Out of the 242 congenital complex cardiac disorders operated upon, 8 developed correction. Thus the incidence of NC in pediatric population in our study was $3.3 \%$, slightly less as compared to the incidence quoted in literature. The incidence of single positive findings in pediatric patient was seen in $75 \%$ while $12.5 \%$ of the patient had more than one positive CT scan finding. In pediatric patients, the commonest (50\%) positive NCCT finding was ischemic infarct and second common finding was SDH (25\%).

\section{Conclusion}

In our retrospective study of the NCCT scan of the head in the immediate and early post-op period, it was found that the CT scan was a very useful imaging tool in timely diagnosing both the FD as well as the NFD complications in patients recently undergone cardiac surgeries; thereby facilitating decision-making and clinical management as indicated. The commonest CT scan finding was ischemic infarct and second most common was SDH along the falx and tentorium. The commonest CT scan finding in FD was ischemic infarct while in NFD was hemorrhage.

Conflict of interest: Nil. 


\section{References}

1. Gordon M (2007) Postoperative Neurological Complications of Cardiovascula Surgery. Sociedad Española de Socorros Mutuos de Mendoza, Mendoza Argentina ( $5^{\text {th }}$ International Congress of Cardiology on Internet).

2. Caplan LR, Hennerici M (1998) Impaired clearance of emboli (washout) is an important link between hypoperfusion, embolism, and ischemic stroke. Arch Neurol 55: 1475-1482.

3. Libman R, Wirkowski E, Neystat M (1996) Stroke associated with cardiac surgery. Determinants, timing and stroke subtypes. Arch Neurol 54: 83-87.

4. Harris DN, Oatridge A, Dob D (1998) Cerebral swelling after normothermic cardiopulmonary bypass. Anesthesiology 88: 340-345.

5. Moody DM, Bell MA, Challa VR (1990) Brain microembolism during cardiac surgery or aortography. Ann Neurol 28: 477-486.

6. Ahlgren E, Aren C (1998) Cerebral complications after coronary artery bypass and heart valve surgery: risk factors and onset of symptoms. J CardiothoracVasc Anesth 12: 270-273.

7. Blossom GB, Fietsam R, Bassett JS (1992) Characteristics of cerebrovascular accidents after coronary artery bypass grafting. Am Surg 58: 584-589.

8. Breuer AC, Furlan AJ, Hanson MR (1983) Central nervous system complications of coronary artery bypass graft surgery: prospective analysis of 421 patients. Stroke 14: 682-687.

9. Carella F, Travaini G, Contri P (1988) Cerebral complications of coronary bypass surgery. A prospective study. ActaNeurol Scand 77: 158-163.

10. Gardner TJ, Horneffer PJ, Manolio TA (1985) Stroke following coronary artery bypass grafting: a ten-year study. Ann Thorac Surg 40: 574-581.

11. Harrison MJ, Schneidau A, Ho R (1989) Cerebrovascular disease and functional outcome after coronary artery bypass surgery. Stroke 20: 235-237.

12. Lynn GM, Stefanko K, Reed JF (1992) Risk factors for stroke after coronary artery bypass. J Thorac Cardiovasc Surg 104: 1518-1523.

13. Roach GW, Kanchuger M, Mangano CM (1996) Adverse cerebral outcomes after coronary bypass surgery. Multicenter Study of Perioperative Ischemia Research Group and the Ischemia Research and Education Foundation Investigators. N Engl J Med 335: 1857-1863.
14. Rorick MB, Furlan AJ (1990) Risk of cardiac surgery in patients with prior stroke. Neurol 40: 835-837.

15. Shaw PJ, Bates D, Cartlidge NE (1985) Early neurological complications of coronary artery bypass surgery. Br Med J (Clin Res Ed) 291: 1384-1387.

16. Sotaniemi KA (1983) Cerebral outcome after extracorporeal circulation Comparison between prospective and retrospective evaluations. Arch Neurol 40: 75-77.

17. Wolman RL, Nussmeier NA, Aggarwal A (1999) Cerebral injury after cardiac surgery: identification of a group at extraordinary risk. Multicenter Study of Perioperative Ischemia Research Group (McSPI) and the Ischemia Research Education Foundation (IREF) Investigators. Stroke 30: 514-522.

18. Beaty CA, Arnaoutakis GJ, Whitman GJ (2013) The Role of Head CT Imaging in the Evaluation of Postoperative Neurologic Deficits in Cardiac Surgery Patients. Ann Thorac Surg 95: 548-554.

19. Kuroda Y, Uchimoto R, Kaieda R (1993) Central nervous system complications after cardiac surgery: A comparison between coronary artery bypass grafting and valve surgery. Anesth Analg 76: 222-227.

20. Vela JLP, González AR, Almodóvar LFL (2005) Neurologic Complications in the Immediate Postoperative Period after Cardiac Surgery. Role of Brain Magnetic Resonance Imaging. Rev EspCardiol 58: 1014-1021.

21. Lev MH1, Farkas J, Gemmete JJ (1999) Acute stroke: improved nonenhanced CT detection--benefits of soft-copy interpretation by using variable window width and center level settings. Radiol 213:150-155.

22. Eastwood JD, Lev MH, Provenzale JM (2003) Perfusion CT with iodinated contrast material. AJR Am J Roentgenol 180: 3-12.

23. Agarwal S, Jones PS, Alawneh JA (2011) Does perfusion computed tomography facilitate clinical decision making for thrombolysis in unselected acute patients with suspected ischemic stroke? Cerebrovasc Dis 32: 227- 233.

24. Pugsley W1, Klinger L, Paschalis C (1994) The impact of microemboli during cardiopulmonary bypass on neuropsychological functioning. Stroke 25: 13931399.

25. Avila-Alvarez A, Gonzalez-Rivera I, Ferrer-Barba A (2012) Acute neurological complications after pediatric cardiac surgery: still a long way to go. An Pediatr (Barc) 76: 192-198. 